\title{
Predicting Unsuccessful Electrical Cardioversion for Acute Atrial Fibrillation (from the AF-CVS Score)
}

Samuli Jaakkola ${ }^{1}$, Gregory YH Lip ${ }^{2}$, Fausto Biancari ${ }^{3}$, Ilpo Nuotio ${ }^{1}$, Juha Hartikainen ${ }^{4}$, Antti Ylitalo $^{1,5}$, KE Juhani Airaksinen ${ }^{1}$

${ }^{1}$ Heart Center, Turku University Hospital and University of Turku, Turku, Finland

${ }^{2}$ University of Birmingham, Institute of Cardiovascular Sciences, City Hospital, Birmingham, United Kingdom

${ }^{3}$ Department of Surgery, Oulu University Hospital, Oulu, Finland;

${ }^{4}$ Heart Center, Kuopio University Hospital, Kuopio, Finland;

${ }^{5}$ Heart Center, Satakunta Central Hospital, Pori, Finland

Word count: words

\section{Corresponding Author:}

Prof. Juhani Airaksinen

Heart Center,

Turku University Hospital,

Turku, Finland

Email: juhani.airaksinen@tyks.fi

tähän varmaankin apurahat 


\section{Abstract}

Objective: To derive and validate a clinical risk stratification tool for identifying patients at high risk for unsuccessful outcome following electrical cardioversion (ECV) for acute atrial fibrillation (AF).

Background: ECV is the standard treatment for acute AF, but identification of patients with increased risk of ECV failure or AF recurrence is of importance for easy clinical decision making. Methods: Data on 2,868 patients undergoing 5,713 cardioversions of acute AF in three Finnish hospitals was included in the analysis. The composite of cardioversion failure and recurrence of AF within 30 days after ECV was recorded. Patients from western ( $n=3716$ cardioversions) and eastern ( $n=1997$ cardioversions) hospital regions were used as derivation and validation datasets, respectively. A clinical scoring system (AF-CVS score) was created using logistic regression analyses with a repeated measures model in the derivation dataset.

Results: A multivariable analysis for prediction of the composite end-point resulted in identification of five clinical variables for increased risk: Age (OR 1.31, 1.13-1.52), not the First AF (OR 1.55, 1.19-2.02), Cardiac failure (OR 1.52, 1.08-2.13), Vascular disease (OR 1.38, 1.11-1.71), and Short interval from previous AF episode (within one month before ECV, OR 2.31, 1.83-2.91). Cindex for this score was $0.67(95 \% \mathrm{Cl}, 0.65-0.69)$ with Hosmer-Lemeshow p-value 0.84 . With high ( $>5$ ) scores (i.e. $12-16 \%$ of the patients), the rate of composite end point was $\sim 40 \%$ in both cohorts and amongst low risk patients (score $<3$ ), the composite end point rate was $\sim 10 \%$.

Conclusions: The risk of failure of ECV and early recurrence of AF can be predicted with simple clinical characteristics. The AF-CVS score is a simple clinical score to aid decision-making in predicting an unsuccessful ECV result.

Key words: atrial fibrillation, cardioversion, recurrence, failure, risk stratification, score. 


\section{Introduction}

Electrical cardioversion (ECV) is the primary method for converting acute atrial fibrillation (AF) into sinus rhythm in the emergency department. Patients presenting with acute AF often experience marked discomfort and various symptoms due to the erratic and elevated heart rate. The good availability of ECV and the effectiveness of successful rhythm conversion in relieving symptoms make ECV an attractive treatment option from physician's and patient's perspective. However, almost $20 \%$ of ECVs are unsuccessful, i.e. the rhythm is not converted or AF recurs within 30 days [10]. In addition, cardioversion and rhythm control strategy increase the risk of thromboembolic complications in patients without adequate anticoagulation and do not offer prognostic advantage over rate control $[6-8,11]$. Since there is limited information on clinical factors contributing to the overall success of ECV our aim was to derive and validate a practical risk scoring system for ECV failure and early AF recurrence in the acute setting based on large multicenter FinCV study data.

\section{Methods}

This study is a part of the multicenter FinCV study (ClinicalTrials.gov Identifier: NCT01380574) assessing the thromboembolic and arrhythmic complications after cardioversion of acute $(<48$ hours) AF [11-13]. The study complies with Declaration of Helsinki and the study protocol was approved by the Medical Ethics Committee of the Hospital District of Southwest Finland and the ethics committee of the National Institute for Health and Welfare. Because of the register-based nature of the study, informed consent of patients was not required. 
All patients ( $>18$ years) with primary diagnosis of AF (ICD-10 code 148.0) admitted to the emergency departments of two university hospitals and one central hospital in western and eastern Finland during the study period were identified from the institutional discharge registers (11).

Databases and emergency clinic admission records were used to review all patients who underwent cardioversion of acute AF. Comprehensive data on type and duration of AF, relevant clinical characteristics, and cardioversion details were collected. Only patients living within the catchment area of the hospitals were selected in order to get adequate follow-up data. In patients with multiple cardioversions, only the first $(<5)$ cardioversions were included in the current analysis, since repetitive cardioversions are redundant in current practice and predict early recurrence [10]. AF episodes lasting over 48 hours were excluded. Thus, there were originally 3,143 patients who underwent 7,660 cardioversions of acute AF. Of those, 5,713 cardioversions in 2,868 patients were qualified ECVs and included in the current analysis.

ECVs were performed according to the contemporary guidelines under general anesthesia [10]. A 12-lead ECG was recorded before and after the procedure. Patients were followed from the patient records for 30 days after the cardioversion to evaluate the recurrence of AF.

The short term failure of ECV was defined as the combination of initial failure of ECV or recurrence of AF within 30 days after ECV. For the purpose of the study, the population was divided in to the derivation (western region) and the validation (eastern region) cohorts according to the location of participating centers (Western Finland, Turku and Pori, n=3716, 65\%; Eastern Finland, Kuopio, $n=1997,35 \%)$. 


\section{Statistical Analysis}

Statistical analyses were performed using SAS 9.4 statistical software (SAS Institutute Inc; Cary; NC). Chi-square test and Wilcoxon nonparametric test were used for bivariable comparisons between groups. The score points were created employing logistic regression analyses with a repeated measures model from the derivation dataset. Covariates with known predictive value (age, gender, duration of the AF episode, AF episodes within 30 days before the index ECV, occurrence of previous AF episode, increasing number of ECV, atherosclerotic vascular disease, heart failure, diabetes, renal failure and history of stroke or TIA or peripheral embolism) $[10,12]$ were initially included in the model and covariates with significance $(<0.05)$ were included in the final model (Table 2). To create the score points the regression coefficients were divided by the smallest coefficient and rounded to the nearest integer [1]. Model calibration was consider acceptable at the Hosmer-Lemeshow goodness-of-fit test $p>0.1$ and model discrimination was evaluated with c-statistics. The predictive ability of the AF-CVS score was then tested in the validation dataset. All tests were two-sided with significance level at $p<0.05$.

\section{Results}

The characteristics of the derivation and validation datasets are presented in Table 1. The overall failure rate (unsuccessful ECV or early recurrence of $A F)$ was higher $(20.5 \%$ vs. $17.8 \%, p<.001)$ in the derivation cohort. In addition, female gender, heart failure and AF within 30 days before the cardioversion were significantly more prevalent in the derivation dataset. In contrast, in the validation cohort there was significantly more hypertension, vascular disease, use of antiarrhythmic medication and first AF episodes. 
The results of multivariable analysis in the derivation dataset (3716 events in 1830 patients) for the prediction of the overall failure of ECV (unsuccessful ECV or early recurrence of AF) are presented in Table 2. The most important score variable was another AF episode within 1 month before ECV $(p<0.001)$. Any prior AF episode $(p<0.001)$, older age $(p<0.001)$, congestive heart failure $(p<0.001)$ and vascular disease $(p<0.001)$ were the other significant predictors included in the developed AF-CVS score.

The c-statistics for the full score was $0.67(95 \% \mathrm{Cl}, 0.65-0.69)$ with Hosmer-Lemeshow p-value 0.84. In both cohorts, the point scores $<3$ show low failure rates $(1.3-13.0 \%)$ and the point scores $>5$ show high failure rates (34.4-66.7\%) (Figure 1). The lowest short-term failure rates were seen in young males having the first AF episode ( $0 \%$ to $6 \%$ in the derivation and validation datasets). The predictive accuracy of AF-CVS score was independent of the use of antiarrhythmic drugs.

\section{Discussion}

To our knowledge this is the first attempt to develop a risk stratification tool for assessing the risk of unsuccessful ECV in the setting of acute AF. Our study shows that the risk of unsuccessful outcome of ECV can be predicted using five simple clinical variables. In patients classified as highrisk patients (cutoff score $>5$ ) the rate of unsuccessful ECV outcome was around $40 \%$ in the derivation and validation cohorts. The c-statistics of the AF-CVS score was 0.67, which is at the same level as in the validation of CHADS- and $\mathrm{CHA}_{2} \mathrm{DS}_{2}$-VASc -scores $[20,21]$. 
The success rate of ECV for acute AF has been reported to vary from $86 \%$ to $96.5 \%[10,18,23-25$,$] ,$ but there is less information on early recurrence rate or predictors of early recurrence after successful ECV [10]. Our present analysis shows that the AF disease "activity" reflected in recent AF episode was the most potent predictor of unfavorable short-term outcome after ECV. Any previous history of AF had additional, but milder negative effect on outcome. In this respect it is noteworthy that the use of antiarrhythmic medication or beta-blockers and high number of earlier ECVs, which reflect the severity of the disease, were also significant predictors for poor outcome in the original population [10], but were not included in the model because of the lack of standard indications for them.

Old age, heart failure and vascular disease were the patient characteristics included in the AF-CVS -score. They are all included also in the $\mathrm{CHA}_{2} \mathrm{DS}_{2}$-VASc score and increase thromboembolic complications if ECV is performed without effective anticoagulation. Female gender was of borderline significance to predict the unsuccessful outcome of ECV. Importantly, female gender is, however, a significant predictor of thromboembolic complications after ECV if no effective anticoagulation is used and also increases the risk of bradyarrhythmic complications together with old age [11-13].

Our findings suggest that the AF-CVS score can be used to identify a patient group with high shortterm failure risk of ECV already in the emergency room and the score may help the clinician to decide the optimal treatment strategy for the patient. Repeated cardioversions may predispose the patient to unnecessary thromboembolic complications, as we know that each cardioversion promotes thrombus formation through atrial stunning [19]. For the high-risk patient group (score $>5$ ), the treatment strategy of rate control may be more justified than rhythm control when more 
definitive treatments (e.g. ablative therapy) are not suitable or available. Of note, the clinical features included in the score (old age, heart failure and vascular disease) are also problematic for antiarrhythmic medication of AF. At the other end of the spectrum, we can similarly identify patients at a low risk for AF recurrence or ECV failure.

As all retrospective studies, our retrospective multicenter analysis has its limitations. Even though the comprehensive electronic patient records have excellent coverage, we were reliant on the data documented by the physician who performed the cardioversion. Also, the recurrence rate of AF is likely to be an underestimation due to potential asymptomatic AF episodes. The AF-CVS score can be applied only for acute $(<48 \mathrm{~h}) \mathrm{AF}$, since the predictors of ECV failure and AF recurrence may differ in elective ECV of AF.

In conclusion, the AF-CVS score is a novel tool to help physicians in choosing the effective treatment strategy for acute AF.

\section{Acknowledgments}

The authors

\section{Disclosures}

None. 
Nämä siis järjestettävä ja luvut korjattava

Table 1. Demographic characteristics.

\begin{tabular}{|c|c|c|c|}
\hline Clinical variables & $\begin{array}{c}\text { Derivation } \\
\text { cohort } \\
(\%)\end{array}$ & $\begin{array}{c}\begin{array}{c}\text { Validation } \\
\text { cohort }\end{array} \\
(\%)\end{array}$ & p-value* \\
\hline$n$ & $3716(65.0)$ & 1997 (34.0) & \\
\hline Event rate & $763(20.5)$ & $355(17.8)$ & 0.01 \\
\hline Age & & & 0.9 \\
\hline$<45 \mathrm{y}$. & $522(14.1)$ & 278 (13.9) & 0.09 \\
\hline 50 to $65 \mathrm{y}$. & $1442(38.8)$ & $832(41.7)$ & \\
\hline$\geq 65 \mathrm{y}$ & $1752(47.2)$ & $887(44.4)$ & \\
\hline Female gender & $1423(38.3)$ & $626(31.4)$ & $<.001$ \\
\hline Hypertension & $1746(47.0)$ & $1067(53.4)$ & $<.001$ \\
\hline Diabetes & $372(10.0)$ & $181(9.1)$ & 0.2 \\
\hline Heart failure & $217(5.8)$ & $63(3.2)$ & $<.001$ \\
\hline Atherosclerotic disease & $876(23.6)$ & $759(38.1)$ & $<.001$ \\
\hline First AF episode & $588(15.8)$ & $823(41.2)$ & $<.001$ \\
\hline AF within last 30 days & $555(15.0)$ & 237 (11.9) & 0.001 \\
\hline Failure of CV & $246(6.6)$ & $90(4.5)$ & 0.001 \\
\hline FA recurrence & $556(15.0)$ & $286(14.3)$ & 0.5 \\
\hline $\begin{array}{l}\text { Antiarrhythmic } \\
\text { medication }\end{array}$ & $477(12.8)$ & $356(17.8)$ & $<.001$ \\
\hline Additive AF-CVS score & $3.8 \pm 1.8$ & $3.3 \pm 1.9$ & $<.001$ \\
\hline
\end{tabular}

AF: atrial fibrillation; Atherosclerosis: coronary artery disease and/or peripheral arterial disease. 
Table 2. Results of multivariable logistic regression analysis with repeated model for prediction of failure for or recurrence after electrical cardioversion. The derivation dataset included 3716 patients.

\begin{tabular}{|c|c|c|c|}
\hline Clinical variables & B-coefficient & $\begin{array}{l}\text { Multivariate } \\
\text { analysis } \\
\text { OR, 95\%Cl }\end{array}$ & Additive score points \\
\hline Age group* & 0.27 & $1.31,1.13-1.52$ & 1 to 2 \\
\hline $\begin{array}{l}\text { Other than the First AF } \\
\text { episode }\end{array}$ & $\begin{array}{l}0.44 \\
0.42\end{array}$ & $\begin{array}{l}1.55,1.19-2.02 \\
1.52,1.08-2.13\end{array}$ & $\begin{array}{l}2 \\
2\end{array}$ \\
\hline Congestive heart failure & 0.32 & $1.38,1.11-1.71$ & 1 \\
\hline $\begin{array}{l}\text { Vascular disease } \\
\text { Short interval (<1 month) } \\
\text { from previous AF episode }\end{array}$ & 0.84 & $2.31,1.83-2.91$ & 3 \\
\hline
\end{tabular}


Figure 1. Incidence of $E C V$ failure and $A F$ recurrence in the derivation and validation datasets.

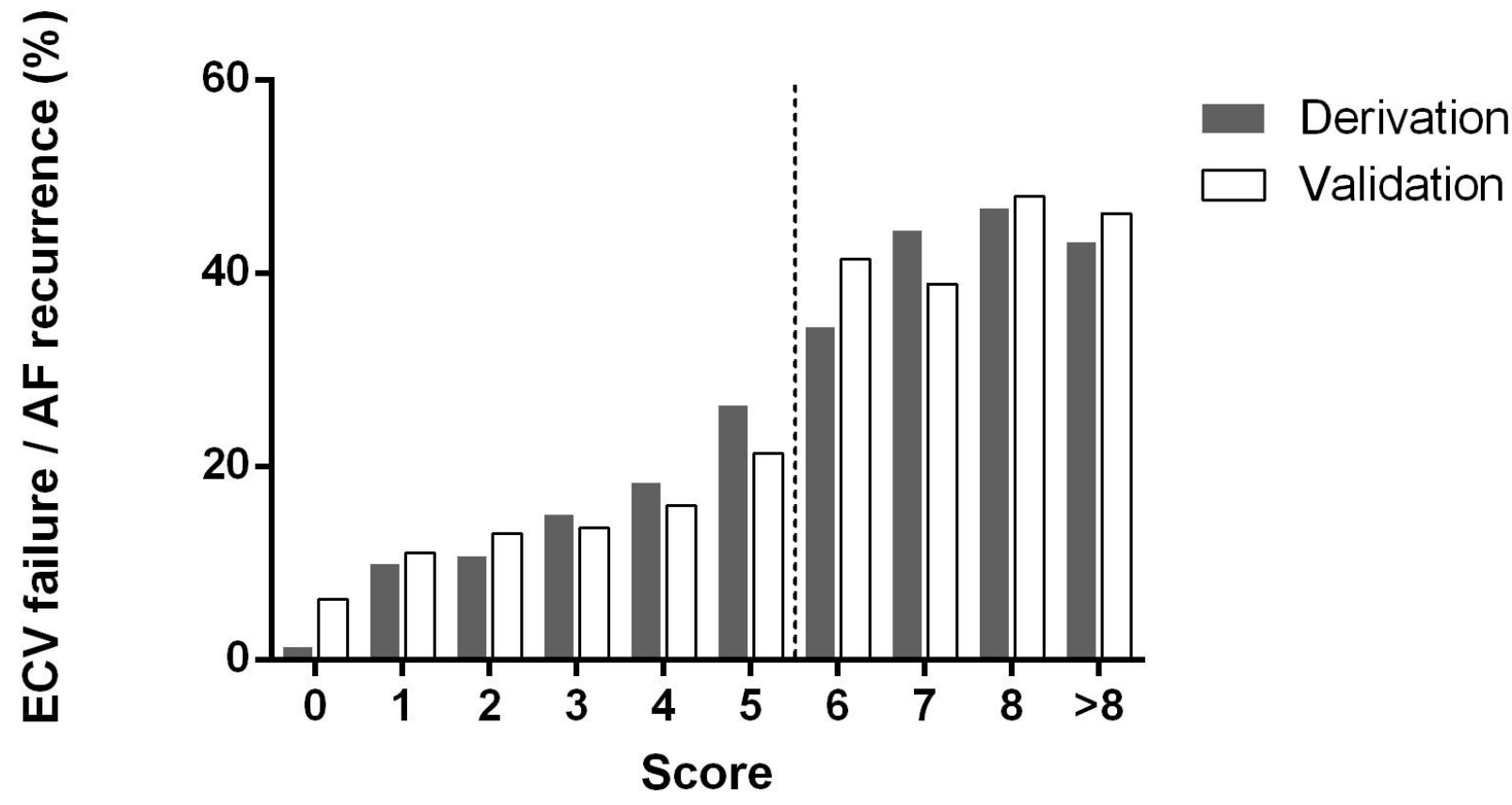

AF-CVS score points:

Age: $<45=0$ points; $45-65=1$ point $;>5=2$ points. First AF episode $?=2$ points if previous AF. $\mathrm{CHF}=2$ points. Vascular disease $=1$ point. Short interval (AF within 1 month $)=3$ points 


\section{References}

[1] Lloyd-Jones DM, Wang TJ, Leip EP ym. Circulation 2004;110:1042-6. Lifetime risk for development of atrial fibrillation: the Framingham Heart Study.

[2] Benjamin EJ, Wolf PA, D'Agostino RB, Silbershatz H, Kannel WB, Levy D Circulation. 1998 Sep 8;98(10):946-52. Impact of atrial fibrillation on the risk of death: the Framingham Heart Study.

[3] Chugh SS1, Havmoeller R, Narayanan K, Singh D, Rienstra M, Benjamin EJ, Gillum RF, Kim YH, McAnulty JH Jr, Zheng ZJ, Forouzanfar MH, Naghavi M, Mensah GA, Ezzati M, Murray CJ. Circulation. 2014 Feb 25;129(8):837-47. Worldwide epidemiology of atrial fibrillation: a Global Burden of Disease 2010 Study.

[4] Camm AJ et al. Europace 2010;12:1360-420. European Heart Rhythm Association, European Association for Cardio-Thoracic Surgery. Guidelines for the management of atrial fibrillation: the Task Force for the Management of Atrial Fibrillation of the European Society of Cardiology (ESC).

[5] Dorian P, Jung W, Newman D et al. J Am Coll Cardiol 2000;36:1303-9. The impairment of health-related quality of life in patients with intermittent atrial fibrillation: implications for the assessment of investigational therapy.

[6] Wyse DG, Waldo AL, DiMarco JP, Domanski MJ, Rosenberg Y, Schron EB, Kellen JC, Greene HL, Mickel MC, Dalquist JE, Corley SD; Atrial Fibrillation Follow-up Investigation of Rhythm Management (AFFIRM) Investigators. N Engl J Med. 2002 Dec 5;347(23):1825-33. A comparison of rate control and rhythm control in patients with atrial fibrillation

[7] Hohnloser SH, Kuck KH, Lilienthal J. Lancet. 2000 Nov 25;356(9244):1789-94. Rhythm or rate control in atrial fibrillation--Pharmacological Intervention in Atrial Fibrillation (PIAF): a randomised trial.

[8] Hagens VE, Crijns HJ, Van Veldhuisen DJ, Van Den Berg MP, Rienstra M, Ranchor AV, Bosker HA, Kamp O, Tijssen JG, Veeger NJ, Van Gelder IC. Am Heart J. 2005 Jun;149(6):1106-11. Rate control versus rhythm control for patients with persistent atrial fibrillation with mild to moderate heart failure: results from the RAte Control versus Electrical cardioversion (RACE) study. 
[9] Camm AJ, Kirchhof P, Lip GY, Schotten U, Savelieva I, Ernst S, Van Gelder IC, Al-Attar N, Hindricks G, Prendergast B, Heidbuchel H, Alfieri O, Angelini A, Atar D, Colonna P, De Caterina R, De Sutter J, Goette A, Gorenek B, Heldal M, Hohloser SH, Kolh P, Le Heuzey JY, Ponikowski P, Rutten FH. Eur Heart J. 2010;31:2369-429. . Guidelines for the management of atrial fibrillation: the Task Force for the Management of Atrial Fibrillation of the European Society of Cardiology

[10] Grönberg T, Hartikainen JE, Nuotio I, Biancari F, Vasankari T, Nikkinen M, Ylitalo A, Airaksinen KE. Can we predict the failure of electrical cardioversion of acute atrial fibrillation? The FinCV study. Pacing Clin Electrophysiol. 2015 Mar;38(3):368-75. Airaksinen KE, Grönberg T, Nuotio I, Nikkinen M, Ylitalo A, Biancari F, Hartikainen JE. J Am Coll Cardiol. 2013 Sep 24;62(13):1187-92. Thromboembolic complications after cardioversion of acute atrial fibrillation: the FinCV (Finnish CardioVersion) study.

[12] Grönberg T, Nuotio I, Nikkinen M, Ylitalo A, Vasankari T, Hartikainen JE, Airaksinen KE. Europace. 2013 Oct;15(10):1432-5. Arrhythmic complications after electrical cardioversion of acute atrial fibrillation: the FinCV study.

[13] Nuotio I, Hartikainen JE, Grönberg T, Biancari F, Airaksinen KE. JAMA. 2014 Aug 13;312(6):647-9. Time to cardioversion for acute atrial fibrillation and thromboembolic complications.

[14] Toso E, Blandino A, Sardi D, Battaglia A, Garberoglio L, Miceli S, Azzarro G, et al. Electrical cardioversion of persistent atrial fibrillation: Acute and long-term results stratified according to arrhythmia duration. Pacing Clin Electrophysiol 2012; 35:1126-1134 Boriani G, Diemberger I, Biffi M, Domenichini G, Martignani C, Valzania C, Branzi A. Electrical cardioversion for persistent atrial fibrillation or atrial flutter in clinical practice: Predictors of long-term outcome. Int J Clin Pract 2007; 61:748-756.

[16] Blich M, Edoute Y. Electrical cardioversion for persistent or chronic atrial fibrillation: Outcome and clinical factors predicting short and long term success rate. Int J Cardiol 2006; 107:389-394.

[17] Kuppahally SS, Foster E, Shoor S, Steimle AE. Short-term and long-term success of electrical cardioversion in atrial fibrillation in managed care system. Int Arch Med 2009; 2:39. 

day outcomes of emergency department patients undergoing electrical cardioversion for atrial fibrillation or flutter. Acad Emerg Med 2010; 17:408-415 R.A. Grimm, W.J. Stewart, J.D. Maloney, et al. Impact of electrical cardioversion for atrial fibrillation on left atrial appendage function and spontaneous echo contrast: characterization by simultaneous transesophageal echocardiography. J Am Coll Cardiol, 22 (1993), pp. 1359-1366

[20] Gregory Y. H. Lip, MD; Robby Nieuwlaat, PhD; Ron Pisters, MD; Deirdre A. Lane, PhD; Harry J. G. M. Crijns, MD. Refining Clinical Risk Stratification for Predicting Stroke and Thromboembolism in Atrial Fibrillation Using a Novel Risk Factor-Based Approach:The Euro Heart Survey on Atrial Fibrillation. Chest 2010;137:263-272 Lip GY, Lane D, Van Walraven C, Hart RG. Additive role of plasma von Willebrand factor levels to clinical factors for risk stratification of patients with atrial fibrillation. Stroke. 2006 Sep;37(9):2294-300. Disertori M, Lombardi F, Barlera S, Latini R, Maggioni AP, Zeni P, Di Pasquale G, Cosmi F, Franzosi MG. Clinical predictors of atrial fibrillation recurrence in the Gruppo Italiano per lo Studio della Sopravvivenza nell'Infarto Miocardico-Atrial Fibrillation (GISSIAF) trial. GISSI-AF Investigators. Am Heart J. 2010 May;159(5):857-63. Bellone A1, Etteri M, Vettorello M, Bonetti C, Clerici D, Gini G, Maino C, Mariani M, Natalizi A, Nessi I, Rampoldi A, Colombo L. Cardioversion of acute atrial fibrillation in the emergency department: a prospective randomised trial. .Emerg Med J. 2012 Mar;29(3):188-91.

[24] Scheuermeyer FX1, Grafstein E, Stenstrom R, Innes G, Heslop C, MacPhee J, Pourvali R, Heilbron B, McGrath L, Christenson J.Thirty-day and 1-year outcomes of emergency 
department patients with atrial fibrillation and no acute underlying medical cause. Ann Emerg Med. 2012 Dec;60(6):755-765

[25] Burton JH, Vinson DR, Drummond K, Strout TD, Thode HC, McInturff JJ. Electrical cardioversion of emergency department patients with atrial fibrillation. Ann Emerg Med $2004 ; 44: 20-30$. 